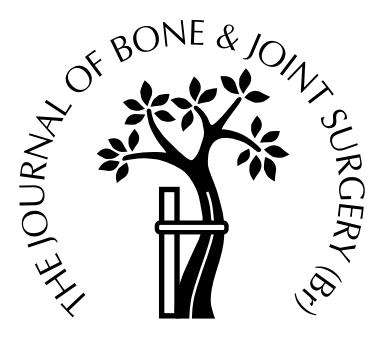

\title{
Secondary resurfacing of the patella for persistent anterior knee pain after primary knee arthroplasty
}

\author{
H. E. Muoneke, A. M. Khan, K. A. Giannikas, E. Hägglund, \\ T. H. Dunningham \\ From Tameside General Hospital, Ashton-under-Lyne, England
}

$\mathbf{O}^{\prime}$ ut of a total of 623 patients who, over a ten-year period, underwent primary total knee replacement (TKR) without patellar resurfacing, 20 underwent secondary resurfacing for chronic anterior knee pain.

They were evaluated pre- and postoperatively using the clinical and radiological American Knee Society score. The mean follow-up was 36.1 months (12 to 104). The mean knee score improved from 46.7 to 62.2 points and the mean functional score from 44.7 to $\mathbf{5 2 . 2}$ points. Only $44.4 \%$ of the patients, however, reported some improvement; the remainder reported no change or deterioration. The radiographic alignment of the TKR did not influence the outcome of secondary resurfacing of the patella. Complications were noted in six of the 20 patients including fracture and instability of the patella and loss of movement.

Anterior knee pain after TKR remains difficult to manage. Secondary resurfacing of the patella is not advocated in all patients since it may increase patient dissatisfaction and hasten revision.

J Bone Joint Surg [Br] 2003;85-B:675-8.

Received 19 August 2002; Accepted after revision 14 February 2003

The dilemma as to whether to resurface the patella during total knee replacement (TKR) remains unresolved. In the early to mid-1970s, resurfacing of the patella was not commonly undertaken. Most prostheses did not have a femoral trochlea and the biomechanics of the patella were essentially ignored until it became apparent that $20 \%$ to $40 \%$ of

H. E. Muoneke, MSc, FRCS, Research Registrar in Trauma and Orthopaedics

A. M. Khan, FRCS, FRCS (Orth), Specialist Registrar in Orthopaedic Surgery

K. A. Giannikas, FRCS, Specialist Registrar in Orthopaedic Surgery

E. Hägglund, RGN BSc, Nurse Practitioner in Orthopaedics

T. H. Dunningham, FRCS, Consultant Orthopaedic Surgeon

Orthopaedic Department, Tameside General Hospital, Fountain Street, Ashton-under-Lyne OL6 9RW, UK.

Correspondence should be sent to Mr K. A. Giannikas.

C 2003 British Editorial Society of Bone and Joint Surgery doi:10.1302/0301-620X.85B5.13787 \$2.00 patients suffered from anterior knee pain (AKP) after TKR. ${ }^{1,2}$ Improved designs reduced the incidence of complications related to the patella from $25 \%$ to $5 \%$ and led to the recommendation that resurfacing of the patella should be standard practice. ${ }^{1-3}$

Subsequent reports showed that resurfacing, however, had complications including loosening of the implant, avascular necrosis, fracture, subluxation or dislocation of the patella, malalignment of the extensor mechanism and AKP. As a result, some authors have suggested selective resurfacing of the patella, ${ }^{4-9}$ although chronic peripatellar pain is still reported in $10 \%$ of patients who undergo TKR without resurfacing. ${ }^{5-8}$ We examined 20 patients with secondary resurfacing of the patella for AKP and now report the results.

Patients and Methods

Between January 1990 and August 2000, 865 patients underwent primary TKR for osteoarthritis. Of these, 623 $(72.0 \%)$ did not have resurfacing of the patella and 20 (3.2\%) had secondary resurfacing for persistent AKP. Those with clinical instability of the patella were excluded.

The mean age of the patients at TKR was 62.2 years (47 to 83 ) and the mean time interval to secondary resurfacing of the patella was 30.9 months (13 to 91). The mean time of follow-up after secondary resurfacing was 36.1 months (12 to 104$)$.

The primary surgical procedure was performed by several surgeons with different levels of experience. The resurfacing procedures were carried out by four consultants, but 13 were managed by or were under the direct supervision, of the senior author (THD). The exposure for both procedures, in all cases, was through a medial parapatellar approach. During the resurfacing procedure, six patients had a lateral retinacular release to improve the tracking of the patella and six had a new polyethylene tray of a similar width. These were precautionary if there was evidence of wear.

The implants in place included 18 of the Kinematic/Kinemax series (Howmedica, Rutherford, New Jersey) of which two were Kinematic, 11 were Kinemax and five were Kinemax-Plus). The remaining two were Miller-Gallante II (Zimmer, Warsaw, Indiana). The Kinematic TKR has an 
'anatomical patellofemoral' articulation similar to the condylar asymmetry of the normal knee, while the Kinemax, Kinemax-Plus and the Miller-Gallante II have a 'symmetrical' configuration of the femoral component.

All patients had been assessed by the American Knee Society (AKS) scoring system ${ }^{10}$ before the primary procedure, four to six months after TKR and before resurfacing of the patella. These scores were recorded by staff of the Physiotherapy Department. Sixteen patients were interviewed by an independent investigator $(\mathrm{EH})$ to establish the long-term results of the patellar resurfacing procedure.

During the review, the AKS score was completed and the patients were questioned about the benefits of the two surgical procedures and their subsequent quality of life. Two patients had died at the time of the review and a further two were unable to attend the clinic, but in all four, the AKS score was available one year after their procedure. Those who could not attend were questioned over the telephone. Two patients had had a tricompartmental revision and their AKS scores before the revision were assessed at the final follow-up and incorporated into the data for analysis. A severity scale, as advocated by Ranawat, ${ }^{1}$ was used to individualise the AKS scores.

All patients had standing anteroposterior and lateral radiographs preoperatively and after TKR and resurfacing of the patella. Skyline views at $30^{\circ}$ of flexion were available in all cases before the resurfacing procedure and at the latest follow-up. Radiological evaluation was done by an independent surgeon (HEM) according to the American Knee Society Roentgenographic Evaluation Scoring System. ${ }^{11}$ The Insall-Salvati ${ }^{12}$ ratio was also calculated and the position of the joint line, according to the method of Figgie et al. $^{13}$

The composite thickness of the patella after resurfacing was measured from the anterior cortex to the anterior margin of the femoral component. All lateral radiographs were within acceptable limits, a minor degree of rotation of the femoral component was unavoidable and affected the accuracy of the measurements of composite thickness of the patella. This was further compounded by our inability to measure the portion of the patellar button which was interposed in the radiodense patellar groove of the femoral component. These results are presented but have not been used for statistical evaluation because of their possible lack of accuracy. On the skyline view, the patellofemoral congruency was measured using the description given by Keblish et al. ${ }^{9}$ Where appropriate, corrections were made for differences in magnification between radiographs using the known measurements of the prosthesis.

Statistical analysis. Comparison between pre- and postoperative resurfacing scores were based on the two-sample Student's $t$-test. Analysis of the relationship between the radiological measurements was based on the Pearson's correlation coefficient. Differences between the mean knee scores of subgroups were determined using analysis of variance.

\section{Results}

All patients showed improvement of both components of the AKS score after TKR. The mean knee score and the function score increased from 37.75 to 62.65 and from 45.25 to 62.65 , respectively. Based on the Ranawat scale, the outcome of surgery was good or excellent in six patients $(30 \%)$, fair in four $(20 \%)$ and poor in ten cases $(50 \%)$. Subjectively only $50 \%$ of patients experienced an improvement in the quality of their life after TKR and only $44.4 \%$ claimed to suffer less pain.

On evaluation before resurfacing, 18 patients (90\%) had a reduced knee score, while $12(60 \%)$ had a reduction in the score for function. The changes in the knee score and the pain and walking ability components of the AKS score were all statistically significant $(\mathrm{p}<0.05)$. At this stage, according to the Ranawat scale, three patients $(15 \%)$ were rated as fair while the remaining $17(85 \%)$ were poor.

After the resurfacing procedure, the knee score of three patients deteriorated, while the pain component decreased in six patients. As a whole, there was improvement in both the overall knee score $(\mathrm{p}=0.013)$ and its pain component $(\mathrm{p}=0.02)$. Regarding the functional score, five patients were worse than they were before the initial knee replacement. The mean functional score increased from 44.7 to 52.2. The mean ability for stair-climbing decreased from 27 to 23 points. Six patients $(30 \%)$ showed a significant improvement, while $14(70 \%)$ either did not improve or became worse. Based on the Ranawat scale, five patients (25\%) now scored as excellent, one (5\%) as good, three $(15 \%)$ as fair and $11(55 \%)$ as poor. Subjectively, $55.5 \%$ claimed to be no better or worse, while the remainder expressed some improvement in their symptoms. Only four claimed to be free from pain. Epidemiological data and the subjective outcome are shown in Table I.

There were complications after the resurfacing procedure in six patients $(30 \%)$. Three developed patellar instability and one sustained a spontaneous fracture which was treated by removal of the patellar component and internal fixation. Three patients had a reduction in the range of movement with an extension lag of $10^{\circ}$. Finally, two required a formal tricompartmental revision because of persistent disability.

Radiological analysis of the TKR is summarised in Table II. There was no evidence of radiolucent lines. The most common radiological feature was malalignment of the femoral component in the sagittal plane (gamma angle), which was present in $75 \%$ of the patients. There was no significant change in patellar height after resurfacing. Patellofemoral congruency was between $63 \%$ and $100 \%$, while only 12 patients $(60 \%)$ were within the recommended range of between $90 \%$ and $100 \%$. Of the remainder, six $(30 \%)$ had some medial tilt, while two $(10 \%)$ had some lateral tilt of the patella. The combined thickness of the patella was between $9 \mathrm{~mm}$ and $18 \mathrm{~mm}$. In two cases, the combined thickness was less than $12.5 \mathrm{~mm}$ and one had a fracture. 
Table I. Epidemiological data and subjective outcome of the patients

\begin{tabular}{|c|c|c|c|c|c|c|}
\hline Case & $\begin{array}{l}\text { Age at } \\
\text { TKR } \\
\text { (yrs) }\end{array}$ & Gender & Prosthesis & $\begin{array}{l}\text { Period to } \\
\text { revision } \\
\text { (mths) }\end{array}$ & $\begin{array}{l}\text { Follow-up } \\
\text { (mths) }\end{array}$ & Outcome \\
\hline 1 & 74 & $\mathrm{~F}$ & Kinematic & 39 & 12 & Deceased \\
\hline 2 & 76 & M & Kinematic & 10 & 125 & No improvement \\
\hline 3 & 73 & $\mathrm{~F}$ & Kinemax & 64 & 20 & Worse - Revision \\
\hline 4 & 50 & M & Kinemax & 26 & 37 & Worse - Revision \\
\hline 5 & 69 & $\mathrm{~F}$ & Miller-Gallante II & 55 & 37 & No improvement (patellar fracture) \\
\hline 6 & 83 & $\mathrm{~F}$ & Miller-Gallante II & 16 & 72 & Improved \\
\hline 7 & 72 & $\mathrm{~F}$ & Kinemax & 55 & 65 & Improved \\
\hline 8 & 65 & M & Kinemax & 23 & 12 & Deceased \\
\hline 9 & 71 & M & Kinemax & 47 & 57 & Improved \\
\hline 10 & 73 & $\mathrm{~F}$ & Kinemax & 24 & 51 & No improvement \\
\hline 11 & 51 & $\mathrm{~F}$ & Kinemax & 13 & 49 & Improved \\
\hline 12 & 77 & $\mathrm{~F}$ & Kinemax & 10 & 42 & Worse \\
\hline 13 & 70 & M & Kinemax & 14 & 40 & No improvement \\
\hline 14 & 73 & $\mathrm{~F}$ & Kinemax & 31 & 35 & Worse \\
\hline 15 & 71 & $\mathrm{~F}$ & Kinemax & 28 & 30 & No improvement \\
\hline 16 & 62 & M & Kinemax-Plus & 91 & 27 & No improvement \\
\hline 17 & 57 & M & Kinemax-Plus & 17 & 27 & Improved \\
\hline 18 & 67 & M & Kinemax-Plus & 18 & 25 & Improved \\
\hline 19 & 72 & $\mathrm{~F}$ & Kinemax-Plus & 19 & 22 & Improved \\
\hline 20 & 47 & M & Kinemax-Plus & 28 & 18 & Improved \\
\hline
\end{tabular}

Table II. Mean changes (n/100 range) in the patients' knee and functional score before and after the surgical interventions

\begin{tabular}{lllll}
\hline Score & $\begin{array}{l}\text { Preknee } \\
\text { arthroplasty }\end{array}$ & $\begin{array}{l}\text { After knee } \\
\text { arthroplasty } \\
\text { (6 to 12 months) }\end{array}$ & $\begin{array}{l}\text { Listing for patellar } \\
\text { resurfacing }\end{array}$ & $\begin{array}{l}\text { Postpatellar } \\
\text { resurfacing }\end{array}$ \\
\hline Mean knee & $37.75(0$ to 55$)$ & $62.25(36$ to 95$)$ & $46.7(31$ to 60$)$ & $62.25(36$ to 94$)$ \\
Mean functional & $45.25(-10$ to 80$)$ & $62.25(45$ to 90$)$ & $44.75(10$ to 65$)$ & $52.25(-10$ to 100$)$ \\
\hline
\end{tabular}

There was one case of an incomplete radiolucent line of 1 $\mathrm{mm}$ at the cement-patella interface.

Overall, each patient in the study group had at least one radiological measurement of the femoral or tibial component outside the recommended range, while ten patients had two and five three aberrant features, respectively. Statistical analysis did not show that a single or combined radiological values had influenced the knee or functional score. Table III shows the radiological measurements of alignment after TKR and patella resurfacing.

\section{Discussion}

The cause of the AKP may be difficult to identify but can often be multifactorial and dramatically compromise the benefits of surgery to a level where the functional disability may exceed that present before the operation.

A possible mechanism may be related to the contact of degenerative or damaged patellar cartilage against the femoral component. Pain fibres are absent in healthy, articular cartilage but have been identified in degenerative cartilage. ${ }^{14}$ It has also been suggested that AKP may be due to an increase of the intraosseous pressure in a degenerative patella, especially during flexion ${ }^{15}$ which may compromise the circulation in the subchondral bone leading to pain. These two hypotheses suggest that resurfacing of the patella
Table III. Radiographic measurements of alignment following primary TKR and patellar resurfacing. The angles refer to the American Knee Society Roentgenographic Evaluation Scoring System

\begin{tabular}{|c|c|c|c|c|}
\hline $\begin{array}{l}\text { Radiographic } \\
\text { measurement }\end{array}$ & Ideal range & Range & Mean & $\begin{array}{l}\text { Patients } \\
\text { within ideal } \\
\text { range } \\
(\mathbf{n}=20)\end{array}$ \\
\hline Alpha angle & $93^{\circ}$ to $97^{\circ}$ & 95 to 102 & 98.3 & 5 \\
\hline Beta angle & $87^{\circ}$ to $93^{\circ}$ & 81 to 92 & 87.7 & 17 \\
\hline Omega angle & $3^{\circ}$ to $7^{\circ}$ valgus & 1 to 9 & 6.1 & 12 \\
\hline Gamma angle & $\begin{array}{l}4^{\circ} \text { flexion } \\
4^{\circ} \text { extension }\end{array}$ & 0 to 21 & 10.5 & 5 \\
\hline Sigma angle & $85^{\circ}$ to $90^{\circ}$ & 80 to 91 & 87.2 & 14 \\
\hline $\begin{array}{l}\text { Change in joint } \\
\text { line }\end{array}$ & $<8 \mathrm{~mm}$ & $-14 \mathrm{~mm}$ to $+9 \mathrm{~mm}$ & & 17 \\
\hline Patellar height & $\begin{array}{l}10 \mathrm{~mm} \text { to } 30 \\
\mathrm{~mm}\end{array}$ & 16 to $36 \mathrm{~mm}$ & 25.5 & 16 \\
\hline Congruency & $90 \%$ to $100 \%$ & & & 12 \\
\hline
\end{tabular}

would eliminate this complication but AKP may still be identified in $5 \%$ of patients who undergo primary TKR with patellar resurfacing. ${ }^{8}$ The poor results of surgery in our study indicate that other factors may be involved.

To the best of our knowledge, Campbell, Mintz and Stevenson ${ }^{16}$ have performed the only existing study which has included cases of resurfacing of the patella as a secondary procedure. Of the six patients described, all of which 
involved the Miller-Gallante I prosthesis, two improved, two were no better, one had patellofemoral subluxation and one a fracture. The authors concluded that the outcome of surgery was unpredictable. Our study confirms these views. Using the Ranawat scale of mean knee scores, only $25 \%$ of patients had an excellent result, $5 \%$ were rated as good, $15 \%$ as fair and $55 \%$ had either no benefit or further deterioration. Subjectively, $25 \%$ of the patients reported deterioration after the secondary surgery.

Inappropriate alignment of either the femoral or tibial component is reported in between $10 \%$ and $30 \%$ of radiological reviews. ${ }^{13,17-20}$ In our study, we found that all patients had at least one radiological measurement outside the recommended range of alignment, suggesting that alignment of the tibial and femoral component, congruency of the patellofemoral articulation and changes in joint line may be important determinants of recurrent AKP. Furthermore, from our series, it is likely that a patient who did not have the patella resurfaced would only develop sufficient anterior knee pain to require secondary resurfacing, if there was malalignment of the primary TKR. It has been reported that AKP may persist when patellar composite thickness exceeds $25 \mathrm{~mm},{ }^{18}$ or when there is an alteration of the joint line by more than $8 \mathrm{~mm} .{ }^{13}$ However, these complications did not appear in our study group.

Statistical analysis of the clinical and functional outcome measures and the radiographic variables failed to identify either a specific factor or a combination of factors which might predict the outcome of the secondary procedure. A notable, radiological concern in our series was the number of cases with increased flexion of the femoral component, suggesting that increased contact stresses on the patella, or distracting forces at the retinaculum especially during knee flexion, might cause AKP.

Salvage of a failed patellar component after primary TKR has a high rate of complications. ${ }^{21}$ Similarly, secondary resurfacing of the patella can be associated with a variety of complications. In our study, $30 \%$ of the patients developed complications, and three required a formal tricompartmental revision procedure.

No benefits in any form have been received or will be received from a commercial party related directly or indirectly to the subject of this article.

\section{References}

1. Ranawat CS. The patellofemoral joint in total condylar knee arthroplasty: pros and cons based on five to ten year follow-up observations. Clin Orthop 1986;205:93-9.

2. Freeman MA, Samuelson KM, Elias SG, et al. The patellofemoral joint in total knee prostheses: design considerations. J Arthroplasty 1989;4(Suppl):S69-74.

3. Insall J, Scott WN, Ranawat CS. The total condylar knee prosthesis: a report of two hundred and twenty cases. J Bone Joint Surg [Am] 1979;61-A:173-80.

4. Barrack RL, Wolfe MW. Patellar resurfacing in total knee arthroplasty. J Am Acad Orthop Surg 2000;8:75-82.

5. Abraham W, Buchanan JR, Daubert H, Greer RB. Should the patella be resurfaced in total knee arthroplasty? Efficiency of patellar resurfacing. Clin Orthop 1988;236:128-34.

6. Brick GW, Scott RD. The patellofemoral component of total knee arthroplasty. Clin Orthop 1988;231:163-78.

7. Cameron HU, Fedorkow DM. The patella in total knee arthroplasty. Clin Orthop 1986;17:231-4.

8. Boyd AD, Ewald FC, Thomas WH, Sledge CB. Long term complications after total knee arthroplasty with or without resurfacing of the patella. J Bone Joint Surg [Am] 1993;75-A:674-81.

9. Keblish PA, Varma AK, Greenwald AS. Patella resurfacing or retention in total knee arthroplasty: a prospective study of patients with bilateral replacements. J Bone Joint Surg [Am] 1994;76-B:930-7.

10. Insall JN, Dorr LD, Scott RD, Scott WN. Rationale of the Knee Society Clinical Rating system. Clin Orthop 1989;248:13-4.

11. Ewald FC. The Knee Society total knee arthroplasty roentgenographic evaluation and scoring system. Clin Orthop 1989;248:9.

12. Insall JN, Salvati E. Patella position in the normal knee joint. Radiology 1971;101:101-4.

13. Figgie HE 3rd, Goldberg VM, Heiple KG, Moller HS 3rd, Gordon NH. The influence of tibiofemoral location on function of the knee in patients with posterior stabilized condylar knee prosthesis. J Bone Joint Surg [Am] 1986;68-A:1035-40.

14. Halata Z, Badalamente MA, Dee R, Propper M. Ultrastructure of sensory nerve endings in monkey (Macaca Fascicularis) knee joint capsule. J Orthop Res 1984;2:169-76.

15. Arnoldi CC, Lemperg RK, Linderholm H. Intraosseous hypertension and pain in the knee. J Bone Joint Surg [Br] 1975;57-B:360-3.

16. Campbell DG, Mintz AD, Stevenson TM. Early patellofemoral revision following total knee arthroplasty. J Arthroplasty 1995;10:287-91.

17. Olcott CW, Scott RD. Femoral component rotation during knee arthroplasty. Clin Orthop 1999;367:39-42.

18. Hsu HC, Luo ZP, Rand JA, An KN. Influence of patella thickness of patellar tracking and patellofemoral contact characteristics after total knee arthroplasty. J Arthroplasty 1996;11:69-80.

19. Berger RA, Crossett LS, Jacobs JJ, Rubash HE. Malrotation causing patellofemoral complications after total knee arthroplasty. Clin Orthop 1998;356:144-53.

20. Merchant AC, Mercer RL, Jacobsen RH, Cool CR. Roentgenographic analysis of patellofemoral congruence. J Bone Joint Surg [Am] 1974;56-A:1391-6.

21. Berry DJ, Rand JA. Isolated patellar component revision of total knee arthroplasty. Clin Orthop 1993;286:110-5. 